\title{
PARTICIPAÇÃO POLÍTICA DE MULHERES NA ADMINISTRAÇÃO PÚBLICA EM MUNICÍPIOS DE GRANDE PORTE DO ESTADO DO RIO GRANDE DO SUL
}

\author{
Caroline Ferri \\ Mara de Oliveira ${ }^{2}$
}

\section{Palavras-Chave}

participação política de

mulheres/secretarias

municipais/representação

política

\section{SUMÁRIO}

\section{Introdução. 2. Retrato da} metodologia utilizada na coleta, organização e análise dos dados. 3. Participação das mulheres junto a secretarias e entes da administração indireta nos municípios de grande porte do Estado do Rio Grande do Sul. 4. Considerações finais. 5 . Referências

\begin{abstract}
Resumo
A desigualdade entre homens e mulheres em funções públicas tem formas históricas e singulares. O presente artigo pretende analisar a participação política das mulheres em cargos públicos, em especial, as secretarias municipais. Por meio de pesquisa aplicada, em uma abordagem de enfoque misto, centra sua análise nos municípios de grande porte do Estado do Rio Grande do Sul, Brasil. Os dados coletados mostram a continuidade da baixa representação política feminina. Dessa forma, concluiu-se que a ocupação dos espaços políticos por mulheres ainda é pequena, e tem-se mantido, em especial, no que se refere ao objeto desta pesquisa, em esferas próprias das chamadas "atividades de cuidado", tais como assistência social e educação.
\end{abstract} Direito. 


\section{THE POLITICAL PARTICIPATION OF WOMEN IN PUBLIC ADMINISTRATION IN THE LARGE MUNICIPALITIES OF THE STATE OF RIO GRANDE DO SUL, BRAZIL}

Caroline Ferri

Mara de Oliveira

Keywords

women's political participation /

municipal departments / political representation

\begin{abstract}
Inequality between men and women in public functions has historical and unique forms. The present article intends to analyze the political participation of women in public functions, in particular, the municipal departments. By means of applied research, using a mixed methodological approach, the analysis focuses on the large municipalities of the State of Rio Grande do Sul, Brazil. Collected data shows the continuity of low female political representation. Thus, it was concluded that the occupation of political spaces by women is still small, and has been maintained, especially with regard to the object of this research, in spheres specific to the so-called "caregiver activities", such as assistance social and education.
\end{abstract}




\section{INTRODUÇÃO}

O tema dessa sistematização refere-se à ocupação política das mulheres em cargos públicos, delimitado, para esse artigo, às funções junto ao executivo, no denominado primeiro escalão. ${ }^{3}$ Diante da finalidade de um artigo científico optou-se em apresentar informações relacionadas a um dos Estados da federação analisados, Rio Grande do Sul (RS), com centralidade naqueles municípios de grande porte, no período do ultimo semestre da legislatura $2012-2016^{4}$, configurando a abrangência geográfica e o período da coleta dos dados.

As atribuições do executivo local, no cumprimento da CF (1988) e demais leis infraconstitucionais, engloba a organização, gestão e prestação de serviços públicos de interesse da população. Para isso, edificam sua estrutura através de distintos órgãos ${ }^{5}$ (secretarias, departamentos, etc.) ou entidades da administração indireta ${ }^{6}$ (fundações, autarquias, empresas públicas, consórcios), compondo o aparelho administrativo.

\footnotetext{
3 Primeiro escalão é terminologia alusiva aos altos cargos comissio nados junto ao executivo (municipal, estadual, federal). Tais cargos, de acordo com a Constituição Federal (CF, 1988, art. 37) abarcam " as funções de confiança, exercidas exclusivamente por servidores ocupantes de cargo efetivo, e os cargos em comissão, a serem preenchidos por servidores de carreira nos casos, condições e percentuai mínimos previstos em lei, destinam-se apenas às atribuições de direção, chefia e assessoramento"; (Redação dada pela Emenda Constitucional $n^{\circ} 19$ de 1998).

${ }^{4}$ Apesar de a coleta de dados ter iniciado em março de 2016, a verificação sobre os (as) titulares das secretarias ocorreu no mês de agosto (antes da eleição), diretamente nos sites dos locais avaliados. O motivo, intencionalmente determinado, de centrar-se tal averiguação em tão só um mês deve-se a menor possibilidade de não haver troca de titularidade.

$5^{\prime \prime} \S 2^{\circ}$ Para os fins desta Lei, consideram-se: I - órgão - a unidade de atuação integrante da estrutura da Administração direta e da estrutura da Administração indireta; II - entidade - a unidade de atuação dotada de personalidade jurídica; [...]". (art. $7^{\circ}$ Lei 9.784/1999 - Regula o processo administrativo no âmbito da Administração Pública Federal). Conforme o Decreto-Lei 200/1967 (Dispõe sôbre a organização da Administração Federal, estabelece diretrizes para a Reforma Administrativa e dá outras providências), a Administração Federal compreende: "I - A Administração Direta, que se constitui dos serviços integrados na estrutura administrativa da Presidência da República e dos Ministérios. II - A Administração Indireta, que compreende as seguintes categorias de entidades, dotadas de personalidade jurídica própria: a) Autarquias; b) Emprêsas Públicas; c) Sociedades de Economia Mista. d) fundações públicas. (Incluído pela Lei nº 7.596, de 1987) (art. $4^{\circ}$ ) e o Código Civil Brasileiro (2002), designadamente artigo 4 "Art. 41. São pessoas jurídicas de direito público interno: I - a União; II - os Estados, o Distrito Federal e os Territórios; III - os Municípios; IV - as autarquias; IV - as autarquias, inclusive as associações públicas; (Redação dada pela Lei n 11.107, de 2005) V - as demais entidades de caráter público criadas por lei".
}

A ocupação desses espaços por mulheres, a exemplo dos cargos eletivos, ainda é pequena7, principalmente, se for levado em conta que elas são a maioria da população. Certamente, a desigualdade entre homens e mulheres em funções públicas tem formas históricase, conforme a conjuntura assume características singulares.

Tais práticas cotidianas encontram-se resumidas no período vivenciado durante a Segunda Guerra Mundial, onde as mulheres, em distintos países, assumiram funções antes determinadas como eminentemente masculinas. Isso, seguramente, causou grande impacto social incluindo a visibilidade concreta, negada durante muitos séculos de que as muIheres não teriam competência, disposição emocional e/ou física de assumir certas funções laborais. Contemporaneamente, a participação das mulheres em diversos postos de trabalho rotulados como apenas varonis (motorista de caminhão e ônibus, mecânica de automóveis, pedreira, carpinteira, piloto de aviões) é uma constante, mesmo que não em igual proporção que a dos homens.

A despeito da multiplicidade de funções desenvolvidas independente de sexo, a desigualdade de gênero é elemento inerente à divisão sexual do trabalho, abrangendo, não obstante, os campos do poder.

A representação social sinalizadora de que há afazeres de natureza feminina e, outros, masculina, é inegável. Persiste a conservadora tradição da divisão de tarefas com a subordinação de gênero. Isso é evidente não somente na execução dessas. O Instituto de Pesquisa Econômica Aplicada (Ipea) ${ }^{8}$

\footnotetext{
7 A investigação percorrida partiu do pressuposto que o preenchimento político de mulheres em cargos públicos executivos de primeiro escalão em nível municipal, secretarias e entidades da administração indireta, ainda é inexpressivo. Isso foi confirmado nos dados obtidos, como poderá ser apreendido na parte 3.

${ }^{8}$ O Ipea é uma fundação pública federal vinculada ao Ministério do Planejamento, Desenvolvimento e Gestão reconhecido nacional e internacionalmente por suas pesquisas fornecedoras de suporte para a formulação e reformulação de políticas públicas e programas de desenvolvimento brasileiros.
} 
demonstra que as mulheres, mesmo as que exercem funções assalariadas, continuam assumindo a dupla jornada ${ }^{9}$ em número expressivamente superior aos homens.

Os indicadores apresentados no documento Retrato das Desigualdades de Gênero e Raça certificam que trabalho doméstico, mesmo o assalariado, é essencialmente feminino. Os dados demonstram que a população brasileira total, ocupada em tal atividade remunerada, por sexo e cor/raça, era de 5.114.050 em 1995 e passou, em 2015, para 6.275.592. Os homens somavam $349.210 \mathrm{em}$ 1995 e 519.992 em 2015, já o número total de mulheres em 1995 era 4.764.840 e em 2015, 5.755.600. (IPEA, 2017, tabela 7.1a1). Então,

O trabalho doméstico sempre foi de responsabilidade das mulheres, para as muIheres de todas as classes. Há, no entanto, uma desigualdade social histórica na forma de enfrentar essa relação. No contexto atual, as mulheres estão cada vez mais inseridas no mercado de trabalho, sem que isso signifique uma transformação na sua relação com o trabalho doméstico. Temos aí uma contradição entre autonomia financeira e sobrecarga de trabalho e de tempo de trabalho em decorrência de uma jornada que compreende trabalho assalariado e trabalho doméstico não assalariado. Para as mulheres que estão exclusivamente no trabalho doméstico não remunerado, a contradição se coloca em outros termos, pois, nesse caso, a falta de uma renda própria é um impedimento à autonomia das mulheres. A divisão sexual

\footnotetext{
A medição da jornada total de trabalho "[...] considera a soma do tempo dedicado ao trabalho remunerado com o tempo dedicado ao trabalho doméstico não remunerado (aos afazeres domésticos), partindo do pressuposto de que ambos produzem bens e/ou serviços necessários para toda a sociedade. Assim, em 2015, a jornada tota média semanal das mulheres superava em 7,5 horas a dos homens $(53,6$ horas semanais a jornada média total das mulheres e 46,1 a dos homens)". (IPEA, 2017a, p. 4).
}

do trabalho dá significado às práticas de trabalho no interior de cada uma de suas esferas. No campo produtivo, há uma concepção sobre o que é o trabalho de homens e o trabalho de mulheres e há uma divisão de tarefas correspondente. Essa divisão incide também sobre o valor do trabalho dos homens e das mulheres, expresso no valor diferenciado e desigual de salários. Além disso, no trabalho produtivo há uma captura das habilidades desenvolvidas no trabalho doméstico que, dessa forma, além de ser apropriado como uma forma de exploração do trabalho das muIheres pode funcionar também como um meio de reafirmar a naturalização dessas habilidades como algo inerente à concepção de um ser feminino e como justificativa da desigualdade salarial. A divisão sexual do trabalho também aparece no interior da esfera do trabalho reprodutivo através da distribuição desigual de trabalho entre mulheres e homens e de uma diferenciação de tarefas. No trabalho reprodutivo, que permanece majoritariamente como encargo das mulheres, quando os homens executam tarefas no trabalho doméstico diretamente relacionadas a necessidades do cuidado, da manutenção da casa e da alimentação, estão em princípio fazendo um trabalho de mulheres. Há tarefas no interior do espaço doméstico consideradas pequenos trabalhos masculinos, ligados à sua habilitação como trabalhador da esfera produtiva. (ÁVILA; FERRREIRA, 2014, p. 18, grifo nosso).

Destarte, a divisão sexual do trabalho envolve questões que vão muito além do desenho e dos critérios como é efetuada a distribuição laboral (por especialidades e atividades, por reconhecimento ou não de 
"merecimento" salarial, pelo desempenho junto a círculos de influência e de decisão).

Entre as atribuições "femininas" reconhecidas socialmente como sendo "merecedoras" de salário (mesmo que não em suas dificuldades e importância) encontra-se o trabalho doméstico, executado por outrem que não um membro da família, comumente, em acordo aos dados apresentados, por mulheres. Independente de pagamento ou não, a essa função cabe as atribuições de limpar, cozinhar, cuidar de crianças, idosos e pessoas com deficiência, configurando, em grande escala, a dupla jornada daquelas que não a exercem maneira remunerada. Os encargos domésticos simbolizam de tal maneira sua conexão a "obrigações" femininas (uma das poderosas formas de opressão e de exploração, destarte de desigualdade), que mesmo quando ele é remunerado os ordenados são baixos. Exemplo disso: o salário mínimo (SM) em 2015 era de $\mathrm{R} \$ 788,00$. No mesmo ano, a média salarial das trabaIhadoras domésticas era de R\$739,50. (IPEA, 2017, tabela 7.11a1).

As descrições e interpretações realizadas até aqui permitem identificar que a divisão sexual do trabalho produz e reproduz a lógica da desigualdade de gênero, uma vez que constitui

[...] a forma de divisão do trabalho social decorrente das relações sociais entre os sexos; mais do que isso, é um fator prioritário para a sobrevivência da relação social entre os sexos. [...] é modulada histórica e socialmente. Tem como características a designação prioritária dos homens à esfera produtiva e das mulheres à esfera reprodutiva e, simultaneamente, a apropriação pelos homens das funções com maior valor social adicionado (políticos, religiosos, militares etc.). [...]. Essa forma particular da divisão social do trabaIho tem dois princípios organizadores: o princípio de separação (existem trabalhos de homens e trabalhos de mulheres) e o princípio hierárquico (um trabalho de homem "vale" mais que um trabalho de muIher). Esses princípios são válidos para todas as sociedades conhecidas, no tempo e no espaço. Podem ser aplicados mediante um processo específico de legitimação, a ideologia naturalista. Esta rebaixa o gênero ao sexo biológico, reduz as práticas sociais a 'papéis sociais' sexuados que remetem ao destino natural da espécie. (HIRATA; KERGOAT, 2007, p.599, grifo nosso).

A baixa presença de mulheres em campos de poder, atrelados ao exercício da política junto ao Estado e os movimentos em nível nacional e internacional, impulsionaram a alteração da Lei 9.504/1997(Estabelece normas para as eleições) tornando obrigatório, o que antes era um indicativo, 30\% (de proporção mínima) à participação do sexo feminino nos pleitos eleitorais. ${ }^{10}$

O texto original da Lei em questão ( $\left(3^{\circ}\right.$ ) mencionava "reserva" de vagas, o que não garantia o seu efetivo preenchimento pelos partidos políticos. O argumento, exposto em vários documentos, inclusive do Tribunal Superior Eleitoral (TSE), era que as reservas eram praticadas, mas as mulheres não as ocupavam. As lutas de vários grupos feministas resultaram na alteração, em 2009, que torna a reserva um imperativo. Isso, entretanto, não tem revelado aumento expres-

o"Art. 10. Cada partido ou coligação poderá registrar candidatos para a Câmara dos Deputados, a Câmara Legislativa, as Assembleias Legislativas e as Câmaras Municipais no total de até $150 \%$ (cento e cinquenta por cento) do número de lugares a preencher [...]§ $3^{\circ}$ Do número de vagas resultante das regras previstas neste artigo, cada partido ou coligação preencherá o mínimo de 30\% (trinta por cento) e o máximo de $70 \%$ (setenta por cento) para candidaturas de cada sexo". (BRASIL, 1997. Lei 9.504. Redação dada pela Lei n 12.034 , de 2009). 
sivo no preenchimento de vagas ao legislativo, executivo e judiciário.

A realidade vivenciada pelas mulheres, nas diferentes faces de desigualdade, demanda a continuidade de pesquisas em andamento e a inserção de outras tantas. Ao coletar dados, organizá-los, descrevê-los e produzir inferências sobre os mesmos (a partir de certas narrativas teóricas veiculadoras de percepções de homem e mundo) apreendem-se condições, modos e interações da vida social. Isso permite desvelar o concreto, o real, que muitas vezes esconde-se em frágeis aparências. A opressão e exploração das mulheres, espelhada em desigualdade(s), ainda é uma equação pouco alterada, o que abarca - consoante ao já assinalado, a ocupação de esferas públicas de poder.

$\mathrm{Na}$ intenção de contribuir com as necessárias reflexões sobre o tema se construiu o presente artigo, realizado por meio de uma metodologia de análise de conteúdo. Ele é sistematizado, além dessa introdução e da conclusão, em duas divisões essenciais. $\mathrm{Na}$ Parte 2, explicita-se a metodologia utilizada, apresentando-se o trajeto percorrido, especialmente nas etapas de coleta e tratamento dos materiais recolhidos, as categorias empíricas edificadas para coleta, descrição e interpretação dos dados e a amostra que resultou no recorte aqui desenvolvido. Na Parte 3, discutem-se os dados apreendidos, em especial no que tange à presença das mulheres em organismos do executivo municipal.

\section{RETRATO DA METODOLOGIA UTILIZADA NA COLETA, ORGANIZAÇÃO E ANÁLISE DOS DADOS}

A metodologia empregada - a partir de pesquisa aplicada - segundo a abordagem do problema foi quanti-qualitativa, também alcunhada de enfoque misto", uma vez que não se enfatizou uma ou outra, mas, efetuou-se mixagem entre elementos numérico-estatísticos e, por exemplo, características demográficas, composição dos espaços do executivo municipal e assunção desses por mulheres etc. Ou seja, nessa abordagem teve-se a possibilidade de recolher materiais "concomitantemente e integrar, ou então fundir os bancos de dados, transformando os temas qualitativos em contagens e comparar essas contagens com dados quantitativos descritivos". (CRESWELL, 2010, p. 244).

O tipo de análise da pesquisa, como um todo, foi o Censo $^{12}$ e, a partir desse, amostra não aleatória intencional13. As fontes, basicamente documentais ${ }^{14}$, oportunizaram a realização da descrição e da interpretação dos dados através da técnica de análise de conteúdo. ${ }^{15}$

Ainda que autores proponham diversificações no processo da análise de conteúdo, nesse estudo, concebe-se como formada de cinco etapas: 1. preparação das informações; 2. unitarização ou transformação do conteúdo em unidades; 3.ordenação das unidades em categorias; 4. descrição; 5. interpretação. "O enfoque misto designa "Um proceso que recolecta, analiza y vincula datoscuantitativos y cualitativos em um mismo estúdio o uma serie de investigaciones para responder a um planteamientodel problema [...]. Se usan métodos de los enfoques cuantitativos y cualitativos y pueden involucrar la conversión de datos cuantitativos en cualitativos y viceversa [...]. Asimismo, el enfoque mixto puede utilizar los dos enfoques para responder distintas preguntas de investigación de un planteamiento del problema". (SAMPIERI; FERNÁNDEZ-COLLADO; LUCIO, 2006, p. 755).

${ }^{12} \mathrm{O}$ Censo envolve a coleta e organização dos dados relativos a todos os municípios, a saber: identificação dos municípios junto ao IBGE - código, gentílico, população 2010, área da unidade territorial 2015 $\left(\mathrm{km}^{2}\right)$, densidade demográfica $2010\left(\mathrm{hab} / \mathrm{km}^{2}\right)$-, site onde estão disponíveis os aspectos individuais de cada cidade, relação nominal das secretarias/entes da administração indireta e, dentre essas aquelas preenchidas por mulheres.

${ }^{13}$ Para a edificação de análises especificas selecionou-se parte da população do censo, 497 (quatrocentos e noventa e sete) municípios, agrupando-os pelo porte (tamanho) segundo as características mencionadas.

14 As principais fontes manuseadas foram: Instituto Brasileiro de Geografia e Estatística (IBGE); Fundação de Economia e Estatística (FEE-RS) e sites oficiais dos municípios avaliados.

${ }^{15}$ Analise de conteúdo em apropriação a Laurence Bardin (2009, p. 42) é efetivada através do uso de "Um conjunto de técnicas de análise das comunicações visando obter, por procedimentos sistemáticos e objetivos de descrição do conteúdo das mensagens, indicadores (quantitativos ou não) que viabilizam a inferência de conhecimentos relativos às condições de produção/recepção (variáveis inferidas) destas mensagens." 
A etapa de preparação das informações demandou, entre outros, a confecção de formulário padrão ${ }^{16}$ (de coleta e organização dos dados) e o estabelecimento dos parâmetros sobre o porte/tamanho das localidades, uma vez que a estrutura administrativa pública faz uso com variadas composições para determinar esses aspectos. De maneira geral, podem-se reunir as classificações enunciadas a seguir.

Classificação A: 1. até 5.000 hab.; 2. de 5.001 a 10.000 hab.; 3. de 10.001 a 20.000 hab.; 4. de 20.001 a 50.000 hab. 5. de 50.001 a 100.000 hab.; 6. de 100.001 a 500.000 hab. 7; mais de $500.000^{17}$.

Classificação B: 1. até 2.500; 2. de 2.501 a 8.000; 3. de 8.001 a 20.000; 4. 20001 a 500.000; 5. mais de $500000^{18}$.

Classificação $C^{19}$ : 1. pequeno porte I, até 20.000 hab.; 2. pequeno porte II, entre 20.001 a 50.000 hab.; 3. porte médio, entre 50.001 a 100.000 habitantes; 4. porte grande, entre 100.001 a 900.000 habitantes; 5. metrópole, superior a 900.000 habitantes.

De maneira geral, ao que interessou a investigação, em sua totalidade, fez-se uso da última classificação (C), observando, sobretudo, as elucidações sobre os portes dos municípios.

[...] entende-se por município de pequeno porte I aquele cuja população chega a 20.000 habitantes (até 5.000 famílias em média). Possuem forte presença de população em zona rural, correspondendo a 45\%

\footnotetext{
Contendo em relação a cada município especificado: site oficial; nome; população; área territorial; densidade demográfica; numero de secretarias/entidades acompanhada da relação nominal e, diante disso a sinalização daquelas com titularidade feminina.

Ver IBGE, 2016

Ver IBGE, 2010

A distribuição utilizada e sua descrição tem sido proposta, de tal maneira, pela política pública de assistência social. Ver Política Nacional de Assistência Social (PNAS), 2004
}

da população total. Na maioria das vezes, possuem como referência municípios de maior porte, pertencentes à mesma região em que estão localizados. Necessitam de uma rede simplificada e reduzida de serviços de proteção social básica, pois os níveis de coesão social, as demandas potenciais e redes socioassistenciais não justificam serviços de natureza complexa.

[...] entende-se por município de pequeno porte /I aquele cuja população varia de 20.001 a 50.000 habitantes (cerca de 5.000 a 10.000 famílias em média). Diferenciam-se do pequeno porte I especialmente no que se refere à concentração da população rural que corresponde a 30\% da população total. Quanto às suas características relacionais mantêm-se as mesmas dos [...] pequenos I.

[...] entende-se por [...] médio porte aqueles cuja população está entre 50.001 a 100.000 habitantes (cerca de 10.000 a 25.000 famílias). Mesmo ainda precisando contar com a referência de municípios de grande porte para questões de maior complexidade, já possuem mais autonomia na estruturação de sua economia, sediam algumas indústrias de transformação, além de contarem com maior oferta de comércio e serviços. A oferta de empregos formais, portanto, aumenta tanto no setor secundário como no de serviços. Esses municípios necessitam de uma rede mais ampla de serviços [...], particularmente na rede [...] básica. Quanto à proteção especial, a realidade [...] se assemelha à dos [...] de pequeno porte, no entanto, a probabilidade de ocorrerem demandas nessa área é maior, o que leva a se considerar a possibilidade de sediarem serviços próprios dessa natureza ou de referência regional, agregando [aqueles] de pequeno porte no seu entorno. 
[...] entende-se por municípios de grande porte aqueles cuja população é de 101.000 habitantes até 900.000 habitantes (cerca de 25.000 a 250.000 famílias). São os mais complexos na sua estruturação econômica, pólos de regiões e sedes de serviços mais especializados. Concentram mais oportunidades de emprego e oferecem maior número de serviços públicos, contendo também mais infra-estrutura. No entanto, [...] por congregarem o grande número de habitantes e, pelas suas características em atraírem grande parte da população que migra das regiões onde as oportunidades são consideradas mais escassas, apresentam grande demanda por serviços das várias áreas de políticas públicas.

[...] entende-se por metrópole os municípios com mais de 900.000 habitantes (atingindo uma média superior a 250.000 famílias cada). Para além das características dos grandes municípios, as metrópoles apresentam o agravante dos chamados territórios de fronteira, que significam zonas de limites que configuram a região metropolitana e normalmente com forte ausência de serviços do Estado. (BRASIL, 2004, p. 16, grifo e separação em itens nossa).

A etapa de unitarização ou transformação do conteúdo em unidades exigiu a releitura minuciosa dos documentos pesquisados, o que permitiu o agrupamento dos dados e a descoberta de novas acepções,bem como a ordenação de unidades de análise em nove grandes categorias empíricas ${ }^{20}$, identificadoras das secretarias ou entidades da admi-

\footnotetext{
As categorias construídas são aqui denominadas empíricas e tem finalidade operacional, visando à organização no processo de coleta, descrição e análise dos elementos apanhados. "Elas têm a propriedade de conseguir apreender as determinações e as especificidades que se expressam [nos documentos selecionados]" (MINAYO, 2004, p. 94). Elas foram arquitetadas a partir de pesquisa exploratória junto a distintos municípios (pequeno, médio e grande porte) do Rio Grande do Sul, o que requereu inúmeras definições/redefinições e testagem.
}

nistração indireta: a) social e ambiental; b) econômica; c) planejamento, infraestrutura urbana e manutenção dos serviços coletivos; d) arrecadação e repasse de dinheiro público; e) organização das competências e funções dos agentes públicos e dos atos administrativos; f) comunicação; g) coordenação de governo; h) mistas; i) sem enquadramento.

A categorização definida, resultado de pesquisa exploratória, consequentemente em procedimento de coleta de dados - em conformidade ao já apontado -, apesar de sua testagem e diversas reformulações, não pode ser entendida como invariável, fixa, imutável, tendo em conta, inclusive a metodologia utilizada. É provável que essas precisem de novas adequações quando da coleta e descrição de dados junto a outros portes/ tamanhos das cidades, ou até mesmo na revisão das informações aqui divulgadas.

Essa é uma questão importante de ser explicitada, pois as categorias em anuência a Roque Moraes (1999) devem ter como diretrizes gerais: validade ${ }^{21}$; exaustividade ou inclusividade ${ }^{22}$; homogeneidade ${ }^{23}$; exclusividade ou exclusão mútua24; objetividade,

\footnotetext{
"A validade ou pertinência exige que todas as categorias criadas sejam significativas e úteis em termos do trabalho proposto, sua problemática, seus objetivos e sua fundamentação teórica. Além disto, todos os aspectos significativos do conteúdo investigado e dos objetivos e problemas da pesquisa devem estar representados [...]. Entre os dois extremos, criar novas categorias e criar categorias úteis e significativas, é preciso atingir um equilíbrio em que o número [...] seja mantido no mínimo necessário. O pesquisador deve ser parcimonioso neste sentido". (MORAES, 1999, p. 7).

2 "da validade, decorre [...] outra regra, a da exaustividade. Dizer que um conjunto de categorias deve ser exaustivo significa dizer que deve possibilitar a categorização de todo o conteúdo significativo definido de acordo com os objetivos da análise. Assim, cada conjunto [...] deve ser exaustivo no sentido de possibilitar a inclusão de todas as unidades de análise". (MORAES, 1999, p. 7).

23 "Dizer que um conjunto de categorias é homogêneo significa poder afirmar que todo o conjunto é estruturado em uma única dimensão de análise. Numa perspectiva quantitativa é dizer que deve basear-se numa única variável. Se houver mais de um nível de análise, o critério de homogeneidade deve estar presente em todos os níveis. Além disto, é importante que esta homogeneidade não seja garantida apenas em conteúdo, mas igualmente em nível de abstração". (MORAES, 1999, p. 7). 24 "Garantida a exaustividade e a homogeneidade de suas categorias, - analista de conteúdo precisa assegurar ainda que cada elemento possa ser classificado em apenas uma categoria. É o critério de exclusividade ou exclusão mútua. Um mesmo dado não pode ser incluído em mais de uma categoria, ou seja, cada elemento ou unidade de conteúdo não pode fazer parte de mais de uma divisão. Para que um conjunto de categorias atenda ao critério da exclusividade é importante que seja construído um conjunto de regras de classificação bem precisas e claras". (MORAES, 1999, p. 8)
} 
consistência ou fidedignidade ${ }^{25}$.

Procurou-se seguir as diretrizes gerais caracterizadas por Roque Moraes (1999), contudo, em um grande número de paginas oficial dos municípios avaliados (grande porte do Estado do Rio Grande do Sul), não havia atribuições e competências dos órgãos/entes, assim como em outros tantos essas continham dubiedades e incoerências, ou mesmo parecidas atribuições entre mais de um setor.

Isso merecerá investigações particulares junto a legislações especificas sobre o tema, a ser efetuado proximamente, o que constituirá outras sistematizações. Diante disso, para o presente momento, optou-se por agrupar as catalogações a partir do nome dessas, não analisando as atribuições/competências a elas devidas.

A denominação preponderante demarca claramente o que "fazem", como secretaria de: cultura; saúde; desenvolvimento econômico; indústria e comercio; administração; turismo; viação e obras públicas; agricultura; finanças; comunicação social. Outras, como: mobilidade urbana, infraestrutura; de governo; desenvolvimento social; proteção social, cidadania, etc. demandaram pesquisa bibliográfica e ao aparato legal que conceituam/examinam tais expressões. Mas, houve uma terceira gama, muito peculiares, assinaladas em apenas uma cidade, que impossibilitam aproximações plausíveis entre as qualificações e as funções, exemplificadas através de secretaria: do interior; do cassino; da pesca; de proteção animal; engenharia e arquitetura.

\footnotetext{
"Quando um conjunto de categorias atende ao critério da objetividade, a classificação não será afetada pela subjetividade dos codificadores. Nestas condições diferentes pesquisadores deverão chegar a resultados semelhantes quando categorizando as mesmas unidades de conteúdo, a partir das mesmas regras de classificação". (MORAES 1999, p. 8).
}

As repartições de cunho social e ambiental estão indicadas na Constituição Federal (1988), nomeadamente, artigos: 6026; 2327; 3028; 196-200 que tratam da saúde pública; 203-204 que dispõe sobre a assistência social, política pública operacionalizadora do direito à "proteção à maternidade e à infância, a assistência aos desamparados" preconizado no art. 6\%; 205-214 demarcador dos direitos e deveres relativos à educação; 215-216-216A, orientadores da cultura enquanto política pública; 217, acerca do desporto; 225 assegurador do direito ao meio ambiente ecologicamente equilibrado; 227-232 que tratam dos direitos da família, da criança, do adolescente, do jovem, do idoso e do índio. Adita-se a esses os direitos relativos às mulheres, designados em vários dispositivos.

A segurança pública - "dever do Estado, direito e responsabilidade de todos, é exercida para a preservação da ordem pública e da incolumidade das pessoas e do patrimônio" (CF, 1988, art. 144) - deve ser cumprida, consoante a Carta Magna, pelas: polícia federal; polícia rodoviária federal; polícia ferroviária federal; polícias civis; polícias militares e corpos de bombeiros militares. Isso denota atri-

\footnotetext{
26 "Art. 6․ São direitos sociais a educação, a saúde, a alimentação, o trabalho, a moradia, o transporte, o lazer, a segurança, a previdência social, a proteção à maternidade e à infância, a assistência aos desamparados, na forma desta Constituição". (CF, 1988, Redação dada pela Emenda Constitucional $n^{\circ}$ 90, de 2015)

27 “Art. 23. É competência comum da União, dos Estados, do Distrito Federal e dos Municípios: [...] II- cuidar da saúde e assistência pública, da proteção e garantia das pessoas portadoras de deficiência; [...] V - proporcionar os meios de acesso à cultura, à educação, à ciência, à tecnologia, à pesquisa e à inovação; (Redação dada pela Emenda Constitucional $n^{\circ} 85$, de 2015); VI - proteger o meio ambiente e combater a poluição em qualquer de suas formas; [...] IX - promover programas de construção de moradias e a melhoria das condições habitacionais e de saneamento básico; X - combater as causas da pobreza e os fatores de marginalização, promovendo a integração social dos setores desfavorecidos". (CF, 1988).

28 "Art 30 Compete aos Municípios: [ ] V - organizar e prestar, diretamente ou sob regime de concessão ou permissão, os serviços públicos de interesse local, incluído o de transporte coletivo, que tem caráter essencial; VI - manter, com a cooperação técnica e financeira da União e do Estado, programas de educação pré-escolar e de ensino fundamental; VI - manter, com a cooperação técnica e financeira da União e do Estado, programas de educação infantil e de ensino fundamental (Redação dada pela Emenda Constitucional $n^{\circ} 53$, de 2006); VII - prestar, com a cooperação técnica e financeira da União e do Estado, serviços de atendimento à saúde da população; [...] IX - promover a proteção do patrimônio histórico-cultural local, observada a legislação e a ação fiscalizadora federal e estadual". (CF, 1988).
} 
buições ligadas diretamente aos entes federados $^{29}$. Assim, notadamente, ao poder local tem sido conferidas atuações de prevenção à violência (instalação de equipamentos públicos, como iluminação, câmeras, etc.), criação de guardas municipais para a proteção de bens, serviços e instalações. Tais obrigações deste âmbito evidenciam atividades que aqui foram convencionadas como planejamento, infraestrutura urbana e manutenção dos serviços coletivos.

As de feição econômica encontram-se registradas nos artigos: $23^{30}$ e 170 conferindo a esfera local contribuir com o Estado e a União,

[...] na valorização do trabalho humano e na livre iniciativa, tem por fim assegurar a todos existência digna, conforme os ditames da justiça social, observados os seguintes princípios: [...] VI - defesa do meio ambiente, inclusive mediante tratamento diferenciado conforme o impacto ambiental dos produtos e serviços e de seus processos de elaboração e prestação; (Redação dada pela Emenda Constitucional $n^{\circ} 42$, de 19.12.2003) VII - redução das desigualdades regionais e sociais; VIII - busca do pleno emprego (CF, 1988, art. 170).

Como se pode perceber no artigo 170 (CF, 1988), dos vários incisos citados apenas um, o VIII, determina ao município a incumbência de ajudar/colaborar com o incremento de aspectos econômicos, o que abrange as diretrizes, as normativas e os incentivos à geração de emprego e renda, arrecada-

\footnotetext{
${ }^{9}$ Nos últimos anos, com o aumento da violência, o governo federal e o Congresso Nacional têm efetuado discussões ampliadas sobre a melhor definição das funções de cada esfera do executivo.

"Art. 23. É competência comum da União, dos Estados, do Distrito Federal e dos Municípios: [...]VIII - fomentar a produção agropecuária e organizar o abastecimento alimentar". (CF, 1988).
}

ção de tributos, criação, absorção, difusão e transferência de tecnologia.

A terceira categorização incluiu os espaços públicos responsáveis pelo planejamento, infraestrutura urbana e manutenção dos serviços coletivos ${ }^{31}$, agregadores das secretarias/ente da administração indireta a quem cabe o planejamento e a infraestrutura das cidades; criação e manutenção dos serviços coletivos (que vão desde a limpeza, coleta de resíduos, água, esgoto, etc.); vigilância dos bens públicos, fiscalização de transito, prevenção à violência, por meio da instalação dos equipamentos públicos, envolvendo a guarda municipal32; melhoria no estabelecimento das relações informacionais internas e externas com a população em geral; condições viárias e de mobilidade; elaboração de projetos de captação de recursos e convênios para investimentos, execução e modernização dos sistemas administrativos e dos serviços. Enfim, engloba seções instituídas à imprescindível qualidade de condições urbanas para uma vida em sociedade.

A área que compreende o que aqui se batizou arrecadação e repasse de dinheiro público reúne conteúdos como: transferência de verbas dos outros entes federados; implementação e monitoramento da política tributaria municipal33; elaboração e acompanhamento da execução de Planos como o plurianual; confecção de contabilidade, balancetes, balanços e relatórios previstos nas legislações federal, estadual e muni${ }^{31}$ As atividades vinculadas a essa categorização encontra eco, também, no já citado art. 30 da CF (1988) especialmente nos incisos: "V - organizar e prestar, diretamente ou sob regime de concessão ou permissão, os serviços públicos de interesse local, incluído o de transporte coletivo, que tem caráter essencial"; e VIII - promover, no que couber, adequado ordenamento territorial, mediante planejamento e controle do uso, do parcelamento e da ocupação do solo urbano". ${ }^{32}$ Lei 13.022, de 8 de agosto de 2014. Dispõe sobre o estatuto geral das guardas municipais.

33 "Art. 30. Compete aos Municípios: I - legislar sobre assuntos de interesse local; [..] III - instituir e arrecadar os tributos de sua competência, bem como aplicar suas rendas, sem prejuízo da obrigatoriedade de prestar contas e publicar balancetes nos prazos fixados em lei". (CF, 1988) 
cipal, além do controle das receitas e das despesas. Isso funda repartições alcunhadas como finanças, receitas, financeira ou fazenda.

O quinto agrupamento, organização das competências e funções dos agentes públicos e dos atos administrativos unifica as ações pertinentes ao controle e desenvolvimento de expedientes administrativos internos e externos e demais procedimentos de ordenamento e/ou patrimônio dessa esfera de governo, e/ou guarda e manutenção de edificações públicas, suas instalações e equipamentos, almoxarifado, processamento das licitações e compras da municipalidade, etc.. Enquadra, também, a coordenação dos recursos humanos e de pessoal e a qualificação dos processos de gestão. Por último, nessa disposição adicionou-se aquelas de idealização e operacionalização de questões relacionadas à infraestrutura e uso das tecnologias de informação e o processamento de dados (internos e externos).

A rotulagem comunicação integra a coordenação das notificações do executivo local junto aos cidadãos e sociedade em geral (canais de mídia, relacionamento com a imprensa, etc.) via repasse de notícias sobre eventos, serviços, enfim, assuntos de interesse dos mais diversos segmentos sociais, realizados pela Prefeitura.

A sétima ordenação, coordenação de governo, abarca o gerenciamento político e estratégico da gestão em vigor através: do monitoramento e implantação das propostas do programa de governo; da articulação com as demais pastas; do assessoramento ao prefeito; da relação institucional com o legislativo e comunidade em geral; da transparência e participação comunitária nas ações públicas.

As secretarias e entes da administração indi- reta convencionada como mistas agrupam dois ou mais campos de variadas categorizações. Nesse sentido, não foram consideradas mistas organismos que apesar de atenderem duas áreas - educação e cultura, habitação e assistência, por exemplo - referiam-se a mesma catalogação, no caso, social e ambiental.

A última categorização, sem enquadramento, reúne aqueles órgãos/entes que não puderam ser incluídos em nenhuma das anteriores, seja pela singularidade ocorrida somente a um município, seja pelo não substantivo esclarecimento pela sua denominação ou (no site) sobre as competências desses. As nomeações dos órgãos registrados como sem enquadramento (cinco lugares, não duplicadas em outros) podem ser visualizadas nos quadros 1 e 2 e suas respectivas apreciações.

Importa ressaltar que a "organização político-administrativa da República Federativa do Brasil compreende a União, os Estados, o Distrito Federal e os Municípios, todos autônomos, nos termos desta Constituição" (CF, 1988, art. 18). Especificamente quanto ao executivo local, a esse não cabe apenas a oferta de bens e serviços públicos (referenciados anteriormente conforme o disposto na CF, 1998 arts. 23 e 30), mas, promover a cidadania e garantir a dignidade da pessoa humana (fundamentos Constitucionais). Isso, no cumprimento dos objetivos fundamentais da República Federativa do Brasil (CF, 1988, art. $\left.3^{\circ}\right)$, demanda contribuir com: a construção de "uma sociedade livre, justa e solidária"; "o desenvolvimento nacional"; a erradicação da pobreza, da marginalização e a redução das desigualdades sociais e regionais; a promoção do "bem de todos, sem preconceitos de origem, raça, sexo, cor, idade e quaisquer outras formas de discrimina- 
ção". O desempenho dessas prerrogativas, consoante ao já apontado, se dá por meio de um aparelho administrativo composto por órgãos e entidades projetados a partir das particularidades locais e das necessidades da população.

\section{PARTICIPAÇÃO DAS MULHERES JUN- TO A SECRETARIAS E ENTES DA ADMI- NISTRAÇÃO INDIRETA NOS MUNICÍPIOS DE GRANDE PORTE DO ESTADO DO RIO GRANDE DO SUL}

Para compreender as inferências produzidas aos dados coletados, indispensável, mesmo que brevemente, contextualizar acerca do Estado analisado. O Rio Grande do Sul, o mais meridional do Brasil, com 11.317.33 (onze milhões, trezentos e dezessete mil e trinta e três) habitantes ${ }^{34}$, possui economia fundada no âmbito da agricultura, da pecuária e da indústria.

No ano de 2013, esse Estado ficou na quinta posição do ranking nacional 35 e, "pela primeira vez em todas as séries de contas regionais já divulgadas [esteve atrás do Paraná]". (IBGE, 2015, p. 11). A quinta posição, em 2013, não denotou melhor rendimento mensal familiar (SMF) per capita - salário mínimo. De acordo com o IBGE (2014), 58,1\% das famílias recebiam, no período examinado, o máximo de dois salários mínimos, assim distribuídos:

"mais de 1 a 2 SMF" (maior percentual obtido), representando 33, 7\%;

"mais de $1 / 2$ até 1 ", totalizando $24,4 \%$;

"até $1 / 4$ ", 2,6\%, "mais de $1 / 4$ até $1 / 2$ ", 8,4\% e os "sem rendimento", traduzindo 1,7\%.

\footnotetext{
34 Informação (atualizada simultaneamente a cada nascimento/óbito) disponível no site http://www.fee.rs.gov.br/, consulta em 08 de maio de 2017 às $15 \mathrm{~h} 16 \mathrm{~min}$

${ }^{35}$ As cinco maiores economias, em 2013 foram: "São Paulo (32,1\%), Rio de Janeiro (11,8\%), Minas Gerais (9,2\%), Paraná $(6,3 \%)$ e Rio Grande do Sul (6,2\%), concentravam 65,6\% do PIB nacional em 2013, quase $2 / 3$ da economia do País". (IBGE, 2015, p. 11)
}

A soma de tais percentuais resulta em $70,8 \%$ das famílias. Ressalta-se que destas 70,8\%, $37,1 \%$ recebem até $1 \mathrm{SMF}^{36}$. Estes dados retratam que amplo contingente de famílias no Rio Grande do Sul, diante do salário mínimo per capta não consegue garantir condições de qualidade de vida dignas.

Aliam-se a estes esclarecimentos, elementos afetos à educação. No RS, em 2013, apenas 12,9\% da população (com 25 anos ou mais) detinha 15 anos ou mais de estudos ${ }^{37}$. O índice preponderante ficou entre 4 a 7 anos de estudo, $29,1 \%{ }^{38}$ e o segundo maior em 11 anos, com 21,4\%39 (IBGE, 2014).

O arranjo administrativo do Rio Grande do Sul comporta 497 (quatrocentos e noventa e sete) municípios, sendo que de grande porte, aqui privilegiados, são em número de dezessete ${ }^{40}$, a saber ${ }^{41}$ : Alvorada, Bagé, Bento Gonçalves, Cachoeirinha, Canoas, Caxias do Sul, Gravataí, Novo Hamburgo, Passo Fundo, Pelotas, Rio Grande, São Leopoldo, Santa Cruz do Sul, Santa Maria, Sapucaia do Sul, Uruguaiana, Viamão. Juntas, estas cidades contavam com 3.591.611 habitantes ${ }^{42}$, totalizando 33,58\% da população estadual ${ }^{43}$.

A coleta de dados junto a cada espaço do Estado avaliado, na classificação grande

\footnotetext{
As divisões utilizadas peloIBGE (2014) são: até 1/4 SMF: mais de 1/4 até $1 / 2$ SMF; $1 / 2$ até 1 SMF; mais de 1 a 2 SMF; 2 a 3 SMF; 3 a 5 SMF; mais de 5 SMF; sem rendimento; sem declaração.

37 Percentual com conexão direta ao ingresso no ensino superior se for considerado a media de oito anos de fundamental e três do médio, o que totalizaria onze anos.

${ }^{38} \mathrm{O}$ que diz respeito ao primeiro grau incompleto.

39 Para aquelas pessoas que cursaram o ensino médio sem reprovações.

40 Dos dezessete municípios apreciados, oito fazem parte da região metropolitana de Porto Alegre, capital do estado. São eles, em ordem alfabética: Alvorada, Cachoeirinha, Canoas, Gravataí, Novo Hamburgo, São Leopoldo, Sapucaia do Sul e Viamão. Juntos, totalizam 1.716.806 habitantes. A Região Metropolitana de Porto Alegre foi criada pela Lei Complementar $n^{\circ} 14$, de 08/06/1973.

Relação em ordem alfabética.

O número de habitantes por município, em ordem crescente, do menos ao mais populoso: Bento Gonçalves, 107.278; Bagé, 116.794; Cachoeirinha, 118.278; Santa Cruz do Sul, 118.374; Uruguaiana, 125.435; Sapucaia do Sul, 130.957: Passo Fundo, 184.826; Alvorada, 195.673; Rio Grande, 197.228; São Leopoldo, 214.087; Novo Hamburgo, 238.940; Viamão: 239.384; Gravataí, 255.660; Santa Maria, 261.031; Canoas, 323.827; Pelotas, 328.275; Caxias do Sul, 435.564. (IBGE, 2016a).

3 Os números acerca da população de cada município se referem ao ano de 2010. Pelo caráter fidedigno do dado, utilizou-se, como total de habitantes, o número de 10.695.532 (IBGE, 2010).
} 
porte, demonstrou uma variabilidade entre no mínimo treze e no máximo vinte uma secretarias/entes. Esta organização numérica se dava na seguinte forma: Alvorada, Bento Gonçalves, Santa Cruz do Sul e Viamão possuíam treze dessas divisões administrativas. Pelotas e Uruguaiana tinham quatorze, Bagé, quinze. Novo Hamburgo e Sapucaia do Sul contavam com dezesseis, enquanto em Passo Fundo eram dezessete. Cachoeirinha, Rio Grande e São Leopoldo computavam dezoito. Santa Maria dezenove, e Canoas vinte. Por fim, Gravataí e Caxias do Sul dispunham de vinte e uma secretarias ou entes da administração indireta.
Estes números apontavam uma diferença relevante em comparação com os de pequeno e médio porte, que se organizam entre cinco e dez secretarias/entes. Infere-se (o que exige outras e aprofundadas investigações) que o fato de utilizarem, amiúde, serviços dos municípios de maior porte (aludido, acima, na descrição sobre a classificação do tamanho desses) define a conveniência de menor número de divisões administrativas.

As dezessete cidades de grande porte, pertencentes ao território gaúcho, dispunham de, conjuntamente, duzentos e setenta e nove secretarias/entes, sintetizadas noquadrol.

\section{Quadro 1 - Municípios de grande porte do RS: quantidade geral de entes e órgãos conforme categorização utilizada}

\begin{tabular}{|c|c|c|c|c|c|c|c|c|c|c|c|c|c|c|c|c|c|c|}
\hline Municípios & 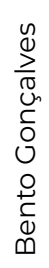 & $\stackrel{\substack{\infty \\
\varpi}}{\infty}$ & 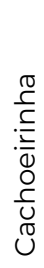 & 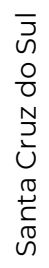 & 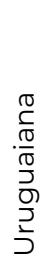 & 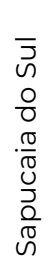 & 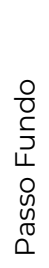 & $\begin{array}{l}\frac{0}{0} \\
\frac{\pi}{0} \\
\frac{0}{2}\end{array}$ & $\begin{array}{l}\frac{0}{O} \\
\frac{C}{0} \\
\frac{D}{U} \\
\frac{0}{\alpha}\end{array}$ & $\begin{array}{l}\frac{0}{0} \\
\frac{0}{0} \\
0 \\
0 \\
1 \\
0 \\
0 \\
ن\end{array}$ & 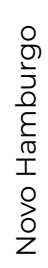 & $\stackrel{\substack{\sigma \\
\varepsilon}}{\stackrel{20}{>}}$ & 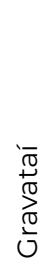 & 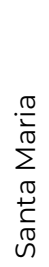 & 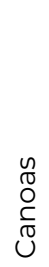 & 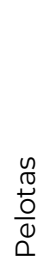 & 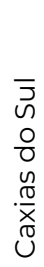 & $\underset{+\stackrel{0}{0}}{\stackrel{0}{0}}$ \\
\hline Social e ambiental & 6 & 8 & 8 & 4 & 6 & 8 & 7 & 5 & 5 & 7 & 7 & 5 & 8 & 6 & 7 & 4 & 7 & 108 \\
\hline Econômica & 3 & 2 & 1 & 2 & 1 & 1 & 1 & 1 & 2 & 1 & 1 & 2 & 2 & 3 & 1 & 2 & 3 & 29 \\
\hline $\begin{array}{l}\text { Planejamento, infraestrutura } \\
\text { urbana e manutenção dos serviços } \\
\text { coletivos... }\end{array}$ & 2 & 3 & 6 & 3 & 3 & 4 & 5 & 2 & 4 & 3 & 3 & 2 & 7 & 4 & 8 & 4 & 6 & 68 \\
\hline $\begin{array}{l}\text { Arrecadação e repasse de dinheiro } \\
\text { público }\end{array}$ & 1 & 1 & 1 & 1 & 1 & 1 & 1 & 1 & 1 & 1 & 1 & 1 & 1 & 1 & 1 & 1 & 2 & 18 \\
\hline $\begin{array}{l}\text { Organização das competências e } \\
\text { funções dos agentes públicos e dos } \\
\text { atos administrativos }\end{array}$ & 1 & 1 & 1 & 1 & 1 & 1 & 2 & 1 & 1 & 2 & 1 & 1 & 1 & 2 & 0 & 0 & 1 & 18 \\
\hline Comunicação & 0 & O & 0 & 1 & 0 & 0 & 0 & 0 & 1 & 0 & 0 & 0 & 0 & 1 & 1 & 0 & 0 & 4 \\
\hline Coordenação de governo & O & 0 & 1 & O & 1 & 1 & $\mathrm{O}$ & 1 & 0 & 2 & 1 & 1 & 2 & 1 & 1 & O & 1 & 13 \\
\hline Mistas & 0 & 0 & 0 & 1 & 1 & 0 & 0 & 2 & 2 & 1 & 1 & 1 & 0 & 1 & 1 & 3 & 1 & 15 \\
\hline Sem enquadramento & 0 & 0 & 0 & 0 & 0 & 0 & 1 & 0 & 2 & 1 & 1 & 0 & 0 & 0 & 1 & 0 & 0 & 06 \\
\hline Total & 13 & 15 & 18 & 13 & 14 & 16 & 17 & 13 & 18 & 18 & 16 & 13 & 21 & 19 & 20 & 14 & 21 & 279 \\
\hline $\begin{array}{l}\text { Órgãos e entes chefiados por } \\
\text { mulheres }\end{array}$ & 4 & 5 & 3 & 4 & 1 & 4 & 3 & 3 & 4 & 4 & 2 & 4 & 4 & 7 & 4 & 1 & 8 & 65 \\
\hline
\end{tabular}


As informações disponíveis no banco de dados da pesquisa revelam que quatro localidades contavam com entes da administração indireta, totalizando nove unidades: cinco fundações (sendo quatro prestadoras de serviços na área social e a mbiental e uma na comunicação); duas autarquias (ambas fazendo parte da catalogação planejamento, infraestrutura urbana e manutenção dos serviços coletivos); duas empresas públicas (uma responsável pela pavimentação, varrição e coleta de resíduos e outra de informática).

Caxias do Sul, com superioridade no número de habitantes possuía uma fundação, uma autarquia e uma empresa pública. Pelotas, Canoas, Santa Maria e Gravataí, respectivamente segunda, terceira, quarta e quinta cidades em numero de moradores, constituíam os outros municípios com entidades dessa natureza.

Na leitura ao quadrol, há duas grandes constatações relacionadas à rotulagem social e ambiental: a) todos os municípios analisados possuíam tais organismos; b) essa é a concentração predominante (cento e oito), o que resulta em $38,70 \%$. A análise ao item "a)" permite identificar que a incidência prevalecente, oito secretarias/entidades, encontrava-se em quatro municípios. A segunda maior ocorrência, com sete secretarias/entidades, abarcava cinco cidades. Em terceiro lugar, seis órgãos/entes, em três municípios. Em quarto, cinco secretarias/entidades em três municípios. Finalmente, dois municípios dispunham da menor quantidade: quatro estruturas reunidas nessa formatação.

Não é por acaso tal concentração. Em conformidade ao afirmado em páginas anteriores, as competências comuns aplicáveis à União, Estados e Municípios indicam a obri- gatoriedade de políticas públicas na área aqui definida como social e ambiental (ver, entre outros, art. 23 da Constituição Federal Brasileira ${ }^{44}$, já mencionado). Particularmente quanto às atribuições privativas ao espaço local ${ }^{45}$, essas agregam o planejamento, organização, prestação, controle e avaliação de serviços ("diretamente ou sob regime de concessão ou permissão, sempre através de licitação, a prestação de serviços públicos" (CF, 1988, art. 175).

A segunda incidência mais expressiva, exposta, também, no quadrol está nas áreas de planejamento, infraestrutura urbana e manutenção dos serviços coletivos (sessenta e oito). Vale observar, que em alguns lugares o número de arranjos dedicados ao tema social e ambiental é muito próximo a essa segunda ocorrência.

Uma divisão simples, entre o numero de organismos e a quantidade de municípios de grande porte estudados, resulta em uma media de quatro secretarias/entes que atuavam junto a essa catalogação, o que nos parece um numero não exagerado, ao contrario, pois essa denominação envolve o exercício de múltiplas atividades, desde o planejamento em si, indispensável ao exercício das funções do poder executivo dessa esfera, assim como a limpeza, coleta de resíduos, água, esgoto, vigilância dos bens públicos, fiscalização de trânsito, condições viárias e de mobilidade, etc.

\footnotetext{
Há na Constituição Federal de 1988, segundo alguns autores, a convivência de duas repartições de competências, uma horizontal e outra vertical. Na horizontal, estariam incluídas aquelas reservadas à União, no campo material e legislativo, pertencendo aos Estados as remanescentes e aos Municípios as determinadas indicativamente (CF, 1988, arts. 21, 22, 25 e 30). A vertical se aplica onde possa haver atuação concorrente dos entes federados. Há previsão da proposição e execução comum, incluindo a atuação concomitante e cooperativa entre os três domínios do executivo (CF, 1988, art. 23). No domínio legislativo, houve definição do estabelecimento das regras gerais a União, suplementadas pelos Estados, Distrito Federal e pelos Municípios (CF, 1988, arts. 24 e 30).

${ }^{45}$ Lembrando que a lógica norteadora do compartilhamento de competências, consoante a legislação pertinente, é o da predominância de interesse. De tal modo, cabem à União as matérias de interesse nacional, aos Estados as regionais e aos Municípios as de interesse local.
} 
Logo, ao lado dos serviços, programas, projetos públicos sociais e ambientais a categorização planejamento, infraestrutura urbana e manutenção dos serviços coletivos está diretamente ligada ao alcance daquelas necessidades básicas da coletividade - essenciais à vida em comunidade -, as quais devem ser providas pelo ente estatal de forma contínua. Todavia, os números e percentuais assinalam a possibilidade de revisão dessa rotulagem e, talvez, na continuidade da pesquisa desmembrá-la separando o planejamento (edificador de atividades meio) da infraestrutura urbana e manutenção dos serviços (operacionalizadores de atividades fins).

Os aparelhos administrativos econômicos exprimiam a terceira predominância, aparecendo em todos os espaços analisados. Eram vinte e nove secretarias com tal classificação, espelhando 10,29\%. O número variava de um a três: oito municípios contavam com apenas um organismo; seis com dois e; três com três estruturas dessa natureza.

A qualificação desenvolvimento econômico - sozinho ou associado a turismo, ciência e tecnologia, inovação, entre outros - foi a de maior manifestação: quinze, das dezessete localidades a utilizavam. Entre as outras designações cita-se: agricultura, pecuária, abastecimento.

Os menores índices de mecanismos públicos veiculadores da economia na seara municipal se devem, certamente, as competências devidas a essa esfera federativa (ver, o já citado, art. 175 da Constituição Federal, 1988). Entretanto, como todas as cidades do Rio Grande do Sul examinadas tinham, no mínimo, uma secretaria atinente, compreende-se que a colaboração local tem sido significativa na promoção de ações de incentivo às empresas (em múltiplas áreas: indústria, comércio, serviços) que gerem emprego, principalmente em épocas de altos índices de desemprego ou subemprego.

Arrecadação e repasse de dinheiro público foi a quarta incidência mais numerosa: dezoito inclusões. Doze cidades mantinham o nome tradicional dado a essa área, Secretaria Municipal da Fazenda, seguidos de outra denominação comumente utilizada, finanças, com três aparições. Em uma municipalidade, tal setor tinha a designação de receita. Apenas Caxias do Sul, contava com duas secretarias para tratar do tema: Gestão e Finanças; Receita Municipal. Apesar de ser uma seção fundamental - sem a qual o executivo estatal não consegue funcionar -, responsável por atividade meio, não é preciso, diversamente daqueles setores da área social e ambiental ou de infraestrutura haver grande quantidade de setores.

No cumprimento das demandas dispostas ao executivo local, é preciso servidores qualificados que planejem, organizem e operacionalizem as atuações conferidas as diferentes unidades de forma que as mesmas não se veiculem como meramente burocráticas, mas com eficiência, eficácia e efetividade.

Para isso, com ênfase à década de 1980, as administrações públicas foram pressionadas a, permanentemente, capacitar, moni- 
torar e avaliar seu quadro de pessoal, o que exigiu a edificação do que se rotulou organização das competências e funções dos agentes públicos e dos atos administrativos. Em todas as dezessete cidades havia um órgão responsável: em onze eram intituladas Secretaria Municipal de Administração; em três a palavra gestão aparecia adjetivada de pública, administrativa, modernização administrativa; em duas congregavam outras áreas como planejamento, finanças; e em uma (Caxias do Sul) havia uma nomenclatura não usada em nenhum outro espaço investigado, Recursos Humanos e Logísticos.

Quanto à catalogação mista não houve nenhuma manifestação em seis cidades. As demais, onze, totalizando quinze secretarias, misturavam áreas, sendo que destas, quatorze órgãos, compunham estruturas sociais e ambientais, que, com certeza, fazem jus a problematizações e interpretações futuras mais consistentes. Um exemplo a ser averiguado é o que agrupa habitação (caracterizada como social e ambiental) com regularização fundiária (nomeada como planejamento, infraestrutura urbana e manutenção dos serviços coletivos) - três inserções - ou habitação e planejamento/ desenvolvimento urbano. Essas se configuram na descrição das competências ou com o que realizam de fato com que área?

A coordenação de governo apareceu em onze localidades. Não obstante, considerando as atribuições estipuladas a essa categorização, é possível que as outras tenham um órgão para implementar essa modalidade de ações, como aquelas vinculadas à chefia de gabinete que, por não se constituir em órgão ou ente da administração indireta, não foi, até o presente momento, estudado.

As estruturas sem enquadramento foram identificadas em cinco lugares e com designações muito específicas, não duplicadas em outro: interior, pesca, cassino, engenharia e arquitetura, proteção animal, diante do que não foram consideradas.

Os organismos de comunicação como secretarias/entes apareceu em quatro municípios. Isso não significa, porém, que não existam mecanismos responsáveis por atividades dessa natureza, uma vez que é comum essas áreas estarem vinculadas ao gabinete do prefeito, coordenação de governo, entre outros, o que requer outras verificações e articulações.

Especificamente ao que interessa a esse artigo, no preenchimento dos cargos de primeiro escalão, a configuração numérica demonstra que das duzentas e setenta e nove secretarias/entes analisados, sessenta e cinco possuíam comando feminino, o que equivale a $23,29 \%$. Esses dados evidenciam o limitado campo de poder político exercido por mulheres - menos de um quarto - confirmando o pressuposto central da pesquisa.

Tais números e percentuais precisam ser apreendidos em seus atributos - no entendimento de que indicam, em muitas situações, questões fundamentais. Para isso construiu-se o quadro 2 . 
Quadro 2 - Ocupação feminina junto às secretarias/entes municipais: quantidades e percentuais

\begin{tabular}{|l|l|l|l|l|}
\hline Categorização & $\begin{array}{l}\mathrm{N}^{\circ} \\
\text { Total de } \\
\text { secretarias/ } \\
\text { Entes }\end{array}$ & $\begin{array}{l}\mathrm{N}^{\circ} \text { de secretarias/ } \\
\text { entes } \\
\text { chefiadas por } \\
\text { mulheres }\end{array}$ & $\begin{array}{l}\text { Porcentagem } \\
\text { da ocupação } \\
\text { feminina (dentro } \\
\text { da categoria) }\end{array}$ & $\begin{array}{l}\text { Porcentagem } \\
\text { (dentre as } \\
\text { secretarias/entes } \\
\text { comandados por } \\
\text { mulheres) }\end{array}$ \\
\hline Social e ambiental & 108 & 41 & $37,96 \%$ & $63,07 \%$ \\
\hline Econômica & 29 & 4 & $13,79 \%$ & $6,15 \%$ \\
\hline $\begin{array}{l}\text { Planejamento, infraestrutura } \\
\text { urbana e manutenção dos serviços } \\
\text { coletivos }\end{array}$ & 68 & 5 & $7,35 \%$ & $7,69 \%$ \\
\hline $\begin{array}{l}\text { Arrecadação e repasse de dinheiro } \\
\text { público }\end{array}$ & 19 & 4 & $21,05 \%$ & $6,15 \%$ \\
\hline $\begin{array}{l}\text { Organização das competências e } \\
\text { funções dos agentes públicos e dos } \\
\text { atos administrativos }\end{array}$ & 18 & 6 & $33,33 \%$ & $9,23 \%$ \\
\hline Comunicação & 4 & 2 & $50,00 \%$ & $3,07 \%$ \\
\hline Coordenação de governo & 13 & 1 & $7,69 \%$ & $1,53 \%$ \\
\hline Mistas & 15 & 2 & $13,33 \%$ & $3,07 \%$ \\
\hline Sem enquadramento & 6 & 0 & $0,0 \%$ & $0,00 \%$ \\
\hline Total & 279 & 65 & Não se aplica & $100 \%(99,96 \%)$ \\
\hline
\end{tabular}

Notas:

1. Elaborada pelas autoras.

2. A sequência das categorizações segue o apresentado na Parte 2, Retrato da metodologia.

Os elementos exibidos no quadro2 demonstram a presença das mulheres em quase todas as classes de secretarias/entes, com exceção de uma, as nomeadas sem enquadramento. Entretanto, também comprovam a secundarização feminina nesses cargos públicos, a exemplo dos de chefia de governo (prefeita, governadora e presidenta da república) e das assembléias legislativas (municipal, estadual e federal).

Adenda-se a essas informações o fato de que todos os dezessete municípios de grande porte do Estado do Rio Grande do Sul tinham secretarias/entes comandado por mulheres: Pelotas e Uruguaiana, uma; Novo Hamburgo, duas; Alvorada, Cachoeirinha e Passo Fundo, três; Bento Gonçalves, Canoas, Gravataí, Rio Grande, Santa Cruz do Sul, São Leopoldo, Sapucaia do Sul, Viamão, quatro; Bagé, cinco; Santa Maria, sete; Caxias do Sul, oito.
Destaca-se que Caxias do Sul, a maior cidade em termos populacionais, era, também,aquela que mais possuía representatividade feminina nestes cargos. Das suas vinte e uma secretarias, oito eram comandadas por mulheres, vindo a expressar um índice de 38,09\%.

Outra reflexão a ser apensada, em observação ao quadro2, é relacionada à área de concentração dessas unidades: aquelas de comando feminino concentravam-se na catalogação social e ambiental (quarenta e uma). Interessante observar que este número, analisando-se comparativamente com o número total de unidades (cento e oito), revelava uma ocupação das mulheres num índice de apenas 37,96\% em relação às por homens.

A qualificação "apenas" encontra sustenta- 
ção no fato de essa categorização agrupar estruturas que nos municípios pesquisados receberam as denominações ${ }^{46}$, individual ou conjugadamente, de: assistência social, cidadania, cultura, educação, esporte, direitos humanos, família, habitação, inclusão social, juventude, lazer, meio ambiente, políticas públicas para a pessoa idosa, políticas para mulheres, saúde, trabalho, envolvendo, amiúde (exceção feita ao meio ambiente), ações, com representação simbólica, ligadas aos cuidados das pessoas, com vínculo orgânico às tarefas ditas femininas (identificado brevemente na Introdução dessa sistematização), o que, nessa lógica, deveria agregar um maior numero/percentual de pessoas do sexo feminino.

Verificou-se que todas as localidades possuíam secretarias/entes que tratam do tema da educação ${ }^{47}$. Destas dezessete aparições, em doze, o comando do órgão era de muIheres, atingindo um percentual de $70,58 \%$. O mesmo sucedia com as destinadas à assistência social ${ }^{48}$, existente em todas as cidades, gerida por mulheres em onze casos, totalizando $64,70 \%$. No caso da saúde, com organismos em todos os municípios, a pasta era comandada por mulheres em oito situações $(47,05 \%)$.

No que se refere às demais categorias de secretarias, a presença feminina era limitada. Naquelas denominadas econômicas, das vinte e nove secretarias que se enquadravam nessa catalogação, estavam as muIheres em quatro delas, perfazendo 13,78\%.

${ }^{46}$ As denominações, em alguns municípios, são diferentes das citadas. Todavia, mediante apreensão de legislação especifica e/ou inferências teóricas, identificou-se essas como congêneres. É o caso da ação social e do desenvolvimento social, traduzidas como assistência social. Mas, isso é tema de reflexão para outro artigo.

Em quatorze municípios a educação possuía secretarias que tratavam exclusivamente deste tema. Em três, interligava-se com outros temas (educação e desporto; educação e cultura; educação, esporte e lazer).

${ }^{48}$ A nomenclatura em questão envolvia: assistência social; desenvolvimento social; inclusão, desenvolvimento social e habitação; acão social e habitação; família, cidadania e assistência social; trabalho, desenvolvimento social e direitos humanos; trabalho e assistência social; cidadania e assistência social.
Já nas vinculadas ao planejamento, infraestrutura urbana e manutenção dos serviços coletivos as mulheres apareciam em cinco das sessenta e oito secretarias, representando $6,4 \%$.

A baixa participação feminina podia ser vista, também, nas categorias arrecadação e repasse de dinheiro público e organização das competências e funções dos agentes públicos e dos atos administrativos. Na primeira, das dezenove inclusões, havia integração de mulheres em quatro secretarias: finanças, fazenda, receita municipal. $\mathrm{Na}$ segunda, de dezoito secretarias, seis eram chefiadas por mulheres.

\section{CONSIDERAÇÕES FINAIS}

Os dados e inferências apresentados propiciam vinculações e análises - assim como apontam a necessidade de coleta de outras tantas informações - a diversos aspectos quanto a escassa ocupação das mulheres em espaços de poder, em pleno século XXI, o que, sem dúvida, confirma as profundas desigualdades de gênero que perpassam a sociedade brasileira.

É evidente o aumento da integração de muIheres em instâncias de poder estatal especialmente no legislativo. Em nível nacional, quanto ao senado, em 2014, dos vinte e sete senadores eleitos, cinco foram mulheres o que correspondeu a 18,5\%, percentual superior ao de 2010, quando dos cinquenta e quatro cargos em disputa, foram eleitas sete senadoras, representando 13\%. Já na câmara federal, nessa mesma legislatura (2014), das quinhentos e treze vacâncias, cinquenta e uma foi preenchido por deputadas, o que equivalia a 9,9\%. São avanços pequenos e até desproporcionais se consi- 
derada a frequência em outras áreas.

Além disso, tais taxas são inferiores à média mundial. A Organização das Nações Unidas (ONU) em parceria com União Interparlamentar (UIP), em seu documento "Mapa das mulheres na política" (lançado em 15 de março de 2017) apontava o Brasil, considerando 174 países, na167ª posição no ranking mundial de participação de mulheres no executivo e na $154^{\mathrm{a}}$ posição, no Congresso Nacional 49.

Salienta-se que a Bulgária, a França e a Nicarágua lideravam o ranking mundial das mulheres com cargos do executivo, com mais de $50 \%$ de representantes femininas. Países como Ruanda, Dinamarca e a África do Sul também se destacaram, ficando, respectivamente, em sétima, oitava e nona posições.

Já na atuação do Congresso Nacional: Ruanda ocupava o primeiro lugar, com $61,3 \%$ de representantes na Câmara e 38,5 \% no Senado; Bolívia encontrava-se em segundo lugar, com 53,1\% na Câmara e 49,9\% no Senado; e Cuba, em terceiro, com 48,9\% na denominada Assembléia Nacional do Poder Popular (nesse país o Parlamento se compõe de um único órgão). O quarto, quinto, sexto, sétimo, oitavo, nono e décimo lugares, nessa ordem, localizavam-se na Islândia, Nicarágua, Suécia, Senegal, Finlândia e África do Sul.

Tais números recomendam a associação entre outros dados (como indicadores de pobreza, desigualdade, Desenvolvimento Humano) entre Países e, no caso do Brasil, entre Estados e municípios, aspectos a serem confrontados no seguimento da pesquisa. Mas, chama-se atenção para o fato de

${ }^{9}$ Dados disponíveis em: https://nacoesunidas.org/brasil-fica-em-167o-lugar-em-ranking-de-participacao-de-mulheres-no-executivo-alerta-onu/. Acesso em: 06 dez 2017. que países com maior e melhor economia ${ }^{50}$, não necessariamente democratizam relações igualitárias de gênero. Ruanda, primeiro lugar em representação de mulheres no legislativo encontrava-se em $158^{\circ}$ lugar (de 189 países) em Desenvolvimento Humano e Bolívia em 118 lugar (UNDP, 2018).

A pesquisa ainda em sua etapa inicial permite conclusões preliminares, porém, os dados coletados confirmam a trajetória histórica das mulheres na vida cotidiana De modo geral, as áreas nas quais as mulheres predominavam nas cidades de grande porte do Estado do Rio Grande do Sul, em 2017, retratam a segregação horizontal em diferentes ocupações, incluindo aquelas relacionadas ao papel de cuidadoras: assistência social e educação, por exemplo.

A subordinação na economia, na política e na seara familiar não sofrerá expressivas alterações "se não se expandir (e muito) uma representação política efetivamente pluralista e se a participação das cidadãs na construção de políticas públicas permanecer limitada" (MATOS, 2011, p. 22).

Em síntese, a opressão às mulheres em suas multifacetadas matizes e desenhos permanece sendo uma máxima a ser enfrentada. Os históricos padrões de desigualdade no acesso ao espaço público permanecem. Diante disso, apesar das várias dúvidas sobre a temática investigada, uma certeza: a pesquisa científica identificadora das muIheres junto aos poderes decisórios e dos motivos, assim como dos impactos para o exercício da cidadania e da democracia ainda é um desafio e, por isso, imprescindível.

${ }^{50}$ As 10 maiores economias do mundo de acordo com o Fundo Monetário Internacional, FMI, em 2017, eram respectivamente, considerando o Produto Interno Bruto (PIB): $7^{\circ}$ Estados Unidos; $2^{\circ}$ China; $3^{\circ}$ Japão; $4^{\circ}$ Alemanha; $5^{\circ}$ Reino Unido; $6^{\circ}$ França; $7^{\circ}$ Índia; $8^{\circ}$ Itália; $9^{\circ}$ Brasil e $10^{\circ}$ Canadá. 
Há uma sub-representação política feminina que deve continuar, com grande ênfase, a ser traduzida nas produções acadêmicas, como teses, dissertações, artigos e pesquisas em geral. É preciso instituir novas formas de aproximação da temática, que possibilite variados momentos de sínteses motivadores de novas indagações e respostas. É mandatário uma alteração na vida institucional, mas também no campo teórico e conceitual afeto, inclusive, ao espaço das universidades.

\section{REFERÊNCIAS}

ÁVILA; M. B.; FERREIRA, V. (2014). Trabalho produtivo e reprodutivo no cotidiano das mulheres brasileiras In: ÁVILA, M. B.; FERREIRA, V. Trabalho remunerado e trabalho doméstico no cotidiano das mulheres (Org.). (pp. 13-50). Recife: SOS Corpo instituto Feminista para a Democracia; Instituto Patrícia Galvão - Mídia e Direitos.

BARDIN, L. Análise de Conteúdo. (2011). São Paulo: Edições 70.

BRASIL. Decreto-Lei 200/1967. Dispõe sôbre a organização da Administração Federal, estabelece diretrizes para a Reforma Administrativa e dá outras providências. Brasília, DF.

Lei 9.504/1997. Estabelece normas para as eleições. Brasília, DF, 30 de setembro de 1997.

Lei 9.784/1999. Regula o processo administrativo no âmbito da Administração Pública Federal. Brasília, DF.

Política Nacional de Assistência Social. Ministério do Desenvolvimento Social. Secretaria Nacional de Assistência Social. Conselho Nacional de Assistência Social. Resolução n 145, de 15 de outubro de 2004 (Dou 28/10/2004).

Lei 13.022/ 2014. Dispõe sobre o estatuto geral das guardas municipais. Brasília, DF.

Constituição da República Federativa do Brasil. Brasília. In: BRASIL, DF, outubro de 1988.

CRESWELL, J. W. (2010).Projeto de pesquisa: métodos qualitativo, quantitativo e misto. 3 ed. Porto Alegre: Artmed.

HIRATA, H; K, D.(2015).Novas configurações da divisão sexual do trabalho.In: Cadernos de Pesquisa,v. 37, n. 132, p. 595-609, set/dez 2007. Disponível emhttp://scielo.br/pdf/cp/v37n132/a0537132. Acesso em: 15 fev. 2017.

IBGE - Instituto Brasileiro de Geografia e Estatística. Censo 2010. 2010. Disponível em https://www.ibge. gov.br/home/estatistica/populacao/censo2010/tabelas_pdf/total_populacao_rio_grande_do_sul.pdf. Acesso em 08 de maio de 2017.

.Síntese de indicadores sociais:uma análise das condições de vida da população brasileira 2014. Estudos e Pesquisas Informação Demográfica e Socioeconômica número 34. Rio de Janeiro, 2014. Disponível em: http://biblioteca.ibge.gov.br/visualizacao/livros/ liv91983.pdf. Acesso em: 23 abr. 2017.

.Contas regionais do Brasil: 2010-2013.Coordenação de Contas Nacionais, número 47. Rio de Janeiro, 2015. Disponível http://biblioteca.ibge.gov.br/visualizacao/livros/liv94952.pdf. Acesso em: 14 abr. 2017.

Perfil dos municípios brasileiros: 2015. Coordenação de População e Indicadores Sociais. - Rio de Janeiro: IBGE, 2016. Disponível em: http://biblioteca.ibge. gov.br/visualizacao/livros/liv95942.pdf. Acesso em: 04 abr. 2017.

Cidades/Rio Grande do Sul - RS. Coordenação de População e Indicadores Sociais. - Rio de Janeiro, 2016a. Disponível em: http://cidades.ibge.gov.br/xtras/ uf.php?coduf=43. Acesso em: 08 mai. 2017.

Renda domiciliar per capita 2016. Diretoria de Pesquisas. 24 de fevereiro de 2017. Disponível em:ftp:// ftp.ibge.gov.br/Trabalho_e_Rendimento/Pesquisa_ Nacional_por_Amostra_de_Domicilios_continua/Renda_domiciliar_per_capita/Renda_domiciliar_per_capita_2016.pdf.

PARTICIPAÇÃO POLÍTICA DE MULHERES NA ADMINISTRACÃO PUUBLICA EM MUNICÍPIOS DE GRANDE PORTE DO ESTADO DO RIO GRANDE DO SUL Caroline Ferri Mara de Oliveira 
IPEA - Instituto de Pesquisa Econômica Aplicada. Retrato das Desigualdades de Gênero e Raça, 19952015. In: BRASIL. Ministério do Planejamento, Desenvolvimento e Gestão, Brasília, DF, 2017. Disponível em: http://www.ipea.gov.br/retrato/indicadores.html. Acesso em: 19 mar. 2017.

Retrato das Desigualdades de Gênero e Raça, 1995-2015. Síntese Resumida.In: BRASIL. Ministério do Planejamento, Desenvolvimento e Gestão, Brasília, DF, 2017a. Disponível em: http://ipea.gov.br/portal/ images/stories/PDFs/170306_retrato_das_desigualdades_de_genero_raca.pdf. Acesso em: 19 mar. 2017.

MATOS, M. (2011). A Subrepresentação Política das Mulheres na chave da sua Subteorização na Ciência Política. In: Denise Paiva. (Org.). Mulheres, Poder e Política: a experiência do Brasil e do Canadá. (pp. 22-54). led, v. 1, Goiânia: Editora da Universidade de Goiás.

(2011a). Mulheres e Política: da cidadania inacabada das mulheres a um projeto de desenvolvimento brasileiro sustentado. In: Ministério das Relações Exteriores. (Org.). Autonomia econômica e Empoderamento da Mulher (pp. 103-121). Oled.Brasília: Ministério das Relações Exteriores, v. 01.

MINAYO, M. C.S. (2008). O desafio do conhecimento: pesquisa qualitativa em saúde. $11^{a}$ ed. São Paulo: Hucitec.

MORAES, Roque. (1999).Análise de conteúdo.Revista Educação(pp.7-32). Porto Alegre, v. 22, n. 37.

(2003). Uma tempestade de luz: a compreensão possibilitada pela análise textual discursiva (pp. 191-211). Revista Ciência \& Educação, v. 9, n. 2.

SAMPIERI, R. H.; FERNÁNDEZ-COLLADO, C.; LUCIO, P. B. (2006). Metodología de la investigación. $4^{a}$ ed. México: McGRAW-HILL.

UNDP - United Nations Development Programme. Human Development Indices and Indicators 2018 Statistical Update. New York, USA, 2018. Disponível em https://www.br.undp.org/content/brazil/pt/home/ library/idh/relatorios-de-desenvolvimento-humano/ relatorio-do-desenvolvimento-humano-2018.html. Acesso em: 01 mai. 2020.
Data de submissão: 03/10/2018

Data de Aceite: 06/05/2020 